\title{
Analysis of the heat and smoke release rate of selected undergrowth types
}

\author{
Marzena Półka ${ }^{1, *}$ \\ ${ }^{1}$ Faculty of Fire Safety Engineering, The Main School of Fire Service in Warsaw, Poland
}

\begin{abstract}
The paper presents the results of tests conducted regarding the flammability and heat release rate (HRR) of selected forest leaf litter under the impact of assumed flux density taking place in fire conditions. Litter samples for testing needs were collected from places characterised by similar biotope parameters. They were collected from 4 types of tree stands: from a cluster of pine trees, beech trees, spruce trees and oak trees. The highest $\mathrm{HRR}_{\max }$ values were obtained during the testing of the spruce litter sample at a thermal exposure of $50 \mathrm{~kW} / \mathrm{m}^{2}$. This suggests, that as compared to the remaining litter types being tested, this litter released the greatest amount of heat in the given time unit and has an evident impact on the rate and magnitude of a forest fire and in an indirect way on the ignition of subsequent leaf litter in adjacent forest zones.
\end{abstract}

\section{Introduction}

Forests are an area of great importance for a correctly functioning ecosystem and natural landscape, which is vitae for human life. For years they have had an advantageous influence on human health and also improved the quality of the natural environment inhabited by diverse living organisms. The data $[1,2]$ indicate that the number of forests on our globe is decreasing at a great pace, which may pose a great hazard for the entire natural ecosystem. That is why it is important to assure good protection of forest areas. The impact of vanishing forests is to a certain extent related to weather conditions which have recently been recorded, such as violent storms, strong winds, droughts etc. These phenomena may cause natural disasters that may have tragic consequences for the flora and fauna, as well as for people. To prevent certain natural disasters, such as fires, their sources should be studied. One of the important factors that affects forest fire spread is the type of undergrowth and its humidity. The litter or the external layer, which as a rule contains easily flammable elements such as fallen twigs,sticks and branches or fresh litterfall made of leaves and needles has a diversified composition, which affects the progress of its biological and thermal decomposition [1-4]. The impact of the flame along with the thermal stream and strong winds are determinant parameters that affect the spreading of a fire. An important element of the fire hazard is the forest litter habitat. Each habitat is characterised by its specific features, which facilitate or hinder the spread of a fire. The thickness of the

\footnotetext{
*Corresponding author: mpolka@sgsp.edu.pl
} 
litter fall depends on the species composition of trees and their age. At the litter bottom is a layer with a significant contents of detritus, which had been formed by strongly decomposed plant material. The rate of such decomposition depends on the humification process. Generally, a characteristic feature of litter comprising elements of coniferous trees is the greater susceptibility to ignition of flammable volatile products. The time until ignition of the flammable gaseous phase obtained from the litter to a large extent depends on the value of external thermal flux.

It is not easy to determine the density of thermal flux necessary to ignite the given flammable material, because each type of litter is formed in different natural environments. As regards undergrowth, a further factor that affects its flammability is humidity, since it is the moisture content that determines the amount of time and heat required to turn flammable material into flame. The higher the humidity, the longer period until ignition is needed $[5,6,7]$. Studies of forest ecosystems flammability have shown that $90 \%$ of all forest fires break out at material humidity equalling 15\%. A limiting threshold, below which fires cannot break out, is a humidity of material over 28\% [1]. Dry forest litter significantly contributes to the initiation of fire and its further spreading. Burning needles prove to be an element that transmits flames very well. They generate a relatively large amount of thermal energy, causing the drying of plant material present in the vicinity. Very important components are cones, small twigs and bark fragments. Large joining areas offlat cone scales with the air cause their easy drying. The moisture content of such cones is low as compared to needles. In addition, cones contain flammable resin materials, which may cause their immediate ignition. An element that determines the flammability of litter is the percentage of lignin and cellulose it contains, and as much as $65 \%$ diverse natural polymers may be found in small dry twigs, cones and outer bark, which are the main component of litter. During decomposition of lignin at a temperature of $128^{\circ} \mathrm{C}$, flammable gaseous products are easily generated, and from cellulose they are generated at temperatures exceeding $200^{\circ} \mathrm{C}[3,5]$.

\section{Description of materials for testing}

For the needs of experimental tests in this work, use was made of samples of forest litter collected in the area of a forestry zone situated in Wodzisław Śląski in the Silesian Region. Litter samples for the needs of studies were collected from places with similar biotope parameters.In this biotope it was noticed that tree clusters which are accessible tend to belong to the second forest age group. Hence, as regards the second age category, the collected litter samples were obtained from 4 types of tree stand: a cluster of pine trees, beech trees, spruce trees and oak trees.

The criterion for selecting the above mentioned samples for testing was the same forest age category.

\section{Characteristic features of the research method}

Studies on the flammability of forest litter were performed with the use of the cone calorimeter method in accordance with the ISO 5660-1:2006 standard, "Reaction-to-fire tests - Heat release, smoke production and mass loss rate" [8]. Pursuant to the above mentioned standard, the flammability analysis consists of determining the heat and smoke release rate from combusted materials subjected to a thermal radiation flux of a specified and required density. The heat release rate is determined through measurements of the oxygen concentration in combustion products. On this basis its use is determined as well as the measurements of the flow of the stream of combustion products. The rate of oxygen use 
during the combustion of samples is proportional to the heat release rate [5].For the majority of flammable materials $13.1 \mathrm{MJ}$ of heat is released per one kilogramme of used material during the combustion of oxygen (with a possible deviation of $5 \%$ for various materials).

\section{Methods of preparing samples for testing}

The collected samples were kept inside a premise for 21 days at an ambient temperature of $20{ }^{\circ} \mathrm{C}$. Each of the samples was weighed to achieve a mass of $30 \mathrm{~g}$. Only in the case of beech was the litter mass only $25 \mathrm{~g}$ due to its large volume. The sample surface exposed to heat radiation was $0.008836 \mathrm{~m}^{2}$ and remained constant for each tested material. The precise sample size was $100 \times 100 \mathrm{~mm}$, and the thickness was $10 \mathrm{~mm}$. Each of the tested samples was wrapped in aluminium foil on the side on which it was not exposed to thermal radiation prior to its being inserted into the holder.

\section{Test results}

The results of the tests were presented in tabular format (Tables1, 2) and as diagrams (Fig. $1,2)$.

Table1. Listing of results for particular samples obtained from cone calorimeter.

\begin{tabular}{|c|c|c|c|c|c|}
\hline $\begin{array}{c}\text { Name of } \\
\text { undergrowth of tree } \\
\text { stands }\end{array}$ & $\begin{array}{c}\text { Thermal } \\
\text { radiation } \\
{\left[\mathrm{kW} / \mathrm{m}^{2}\right]}\end{array}$ & $\begin{array}{c}\mathrm{HRR}_{\max } \\
{\left[\mathrm{kW} / \mathrm{m}^{2}\right]}\end{array}$ & $\begin{array}{c}\mathrm{HRR}_{\mathrm{av}} \\
{\left[\mathrm{kW} / \mathrm{m}^{2}\right]}\end{array}$ & $\begin{array}{c}\mathrm{THR} \\
{\left[\mathrm{MJ} / \mathrm{m}^{2}\right]}\end{array}$ & $\begin{array}{c}\mathrm{T}_{\mathrm{z}} \\
{[\mathrm{s}]}\end{array}$ \\
\hline Spruce & 25 & 22 & 13 & 15 & No ignition \\
\hline Spruce & 30 & 30 & 19 & 15 & No ignition \\
\hline Spruce & 35 & 32 & 22 & 26 & No ignition \\
\hline Spruce & 45 & 37 & 30 & 35 & No ignition \\
\hline Spruce & 50 & 240 & 161 & 46 & 4 \\
\hline Pine & 40 & 185 & 92 & 36 & 10 \\
\hline Pine & 35 & 196 & 89 & 42 & 12 \\
\hline Pine & 30 & 31 & 19 & 20 & No ignition \\
\hline Oak & 40 & 146 & 90 & 12 & 2 \\
\hline Oak & 35 & 105 & 55 & 14 & 8 \\
\hline Oak & 30 & 32 & 22 & 18 & No ignition \\
\hline Beech & 35 & 31 & 23 & 7 & No ignition \\
\hline Beech & 40 & 98 & 55 & 13 & 10 \\
\hline
\end{tabular}

Table 2. Specification of test results.

\begin{tabular}{|c|c|c|c|c|c|c|}
\hline $\begin{array}{c}\text { Name of } \\
\text { undergrowth } \\
\text { of tree stands }\end{array}$ & $\begin{array}{c}\text { Thermal } \\
\text { radiation } \\
{\left[\mathrm{kW} / \mathrm{m}^{2}\right]}\end{array}$ & $\begin{array}{c}\text { Bulk } \\
\text { density } \\
{\left[\mathrm{g} / \mathrm{cm}^{3}\right]}\end{array}$ & $\begin{array}{c}\text { Rate of } \\
\text { sample mass } \\
\text { decrease } \\
\text { MLR }[\mathrm{g} / \mathrm{s}]\end{array}$ & $\begin{array}{c}\text { \% of sample } \\
\text { mass decrease } \\
\text { ML }[\%]\end{array}$ & $\begin{array}{c}\text { SPR } \\
{\left[\mathrm{m}^{2} / \mathrm{s}\right]}\end{array}$ & $\begin{array}{c}\text { Emission } \\
\text { of COav } \\
{[\mathrm{kg} / \mathrm{kg}]}\end{array}$ \\
\hline Spruce & 25 & 0.3395 & 2.91 & 30.8 & 0.0236 & 1.303 \\
\hline Spruce & 30 & 0.3395 & 0.09 & 29.5 & 0.0411 & 1.327 \\
\hline Spruce & 35 & 0.3395 & 0.18 & 67 & 0.0684 & 1.501 \\
\hline
\end{tabular}




\begin{tabular}{|c|c|c|c|c|c|c|}
\hline Spruce & 45 & 0.3395 & 0.25 & 69.4 & 0.1156 & 1.545 \\
\hline Spruce & 50 & 0.3395 & 0.3 & 69 & 0.0337 & 1.063 \\
\hline Pine & 40 & 0.3395 & 0.24 & 72.6 & 0.1351 & 1.063 \\
\hline Pine & 35 & 0.3395 & 0.19 & 68.6 & 0.0894 & 1.1 \\
\hline Pine & 30 & 0.3395 & 4.74 & 89.3 & 0.0755 & 1.528 \\
\hline Oak & 40 & 0.3395 & 1.11 & 91.5 & 0.0271 & 1.131 \\
\hline Oak & 35 & 0.3395 & 0.15 & 68.6 & 0.0754 & 1.243 \\
\hline Oak & 30 & 0.3395 & 0.2 & 62.3 & 0.0428 & 1.267 \\
\hline Beech & 35 & 0.3395 & 0.08 & 49.5 & 0.0812 & 1.486 \\
\hline Beech & 40 & 0.3395 & 0.11 & 62 & 0.0886 & 1.295 \\
\hline
\end{tabular}

\section{Review of results and conclusions}

The research problem related to the analyses of the heat and smoke release rate proved to be complicated primarily owing to a lack of uniformity of materials used for testing. After the completion of initial testing it was assumed in the work that the same masses of litter samples would be tested at a layer height $10 \mathrm{~mm}$. The results of litter flammability were obtained based on these assumptions and are shown in Table1.

The obtained results allow the presumption that the lowest density of thermal flux for the assumed conditions of sample piling conditions and their qualitative components amounts to $35 \mathrm{~kW} / \mathrm{m}^{2}$ for pine and oak. The higher value of external heat stream, at which the sample became ignited, has been obtained for spruce litter, namely $-50 \mathrm{~kW} / \mathrm{m}^{2}$. On the other hand, for beech litter the external thermal flux density falling on the sample at which an ignition has taken place was $40 \mathrm{~kW} / \mathrm{m}^{2}$. Based on the obtained results it may be presumed that pilot ignition of the gaseous phase for the studied types of litter is possible in thermal expositions within the range of 35 and $40 \mathrm{~kW} / \mathrm{m}^{2}$. At those values all samples ignited. Taking into account diagram (Figure 1), $H R R_{\max }$, may be observed, which is already achieved after several minutes afte commencement of the measurement, and gradually becomes reduced below $50 \mathrm{~kW} / \mathrm{m}^{2}$ after ca. $120 \mathrm{~s}$.

The highest value of $\mathrm{HRR}_{\max }$ was reached by spruce litter -amounting to almost 250 $\mathrm{kW} / \mathrm{m}^{2}$ at thermal flux density following the research material-50 $\mathrm{kW} / \mathrm{m}^{2}$. A lower HHR max value was achieved by samples of pine litter, with similar values. Lower values of $H_{H R}$ max below $150 \mathrm{~kW} / \mathrm{m}^{2}$ were obtained for litter of deciduous trees, oak and beech respectively. Between the lowest and the highest value of $\mathrm{HRR}_{\max }$ this was a difference amounting to almost $250 \%$ in relation to the lowest value. After reaching $H_{R R} R_{\max }$ (Fig. 1), the values of the heat release rate tended to decrease, and then after the vanishing of flame combustion they were maintained at an even level for a certain time. The highest HRR values occur when ignition of the tested material takes place. Given similar thermal exposures $\left(35-40 \mathrm{~kW} / \mathrm{m}^{2}\right)$, it may be presumed that among the tested litters the highest dynamics of heat release were recorded for pine litter by ca. $25 \mathrm{~kW} / \mathrm{m}^{2}$ higher as compared to oak and beech litter (at exposure equalling to $40 \mathrm{~kW} / \mathrm{m}^{2}$ ). On the other hand, at an exposure of $50 \mathrm{~kW} / \mathrm{m}^{2}$ spruce litter has an $\mathrm{HRR}_{\max }$ of $240 \mathrm{~kW} / \mathrm{m}^{2}$; this value cannot be related to the other litters, because the others have not been tested at such exposure. 


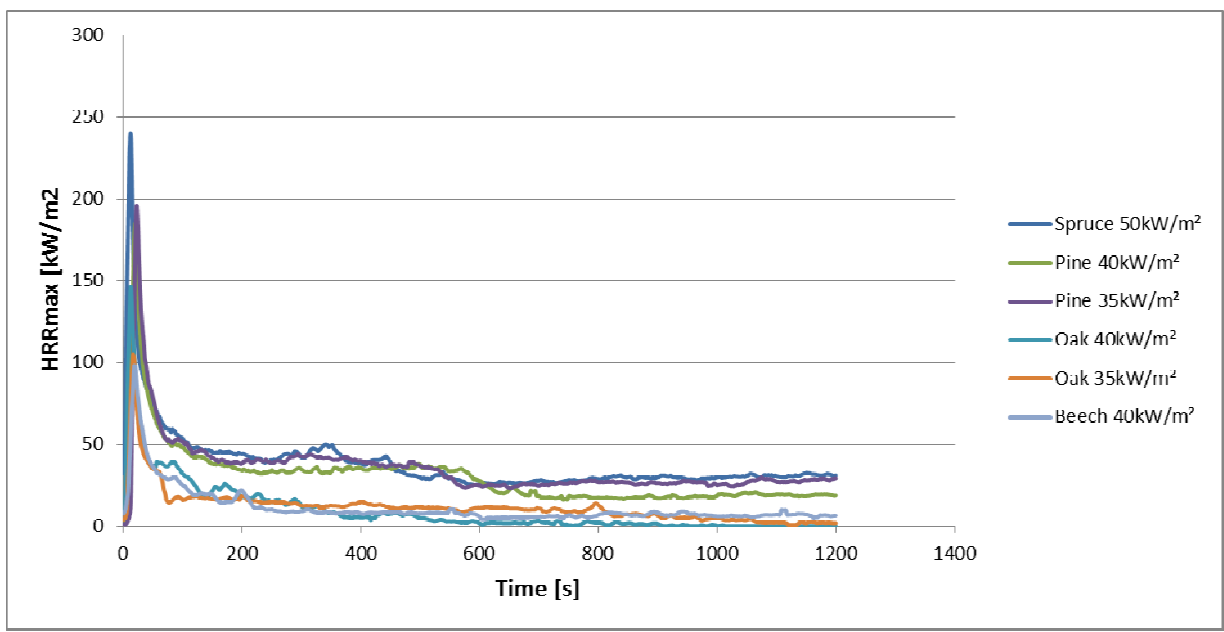

Fig. 1. Values of heat release rates of the tested materials.

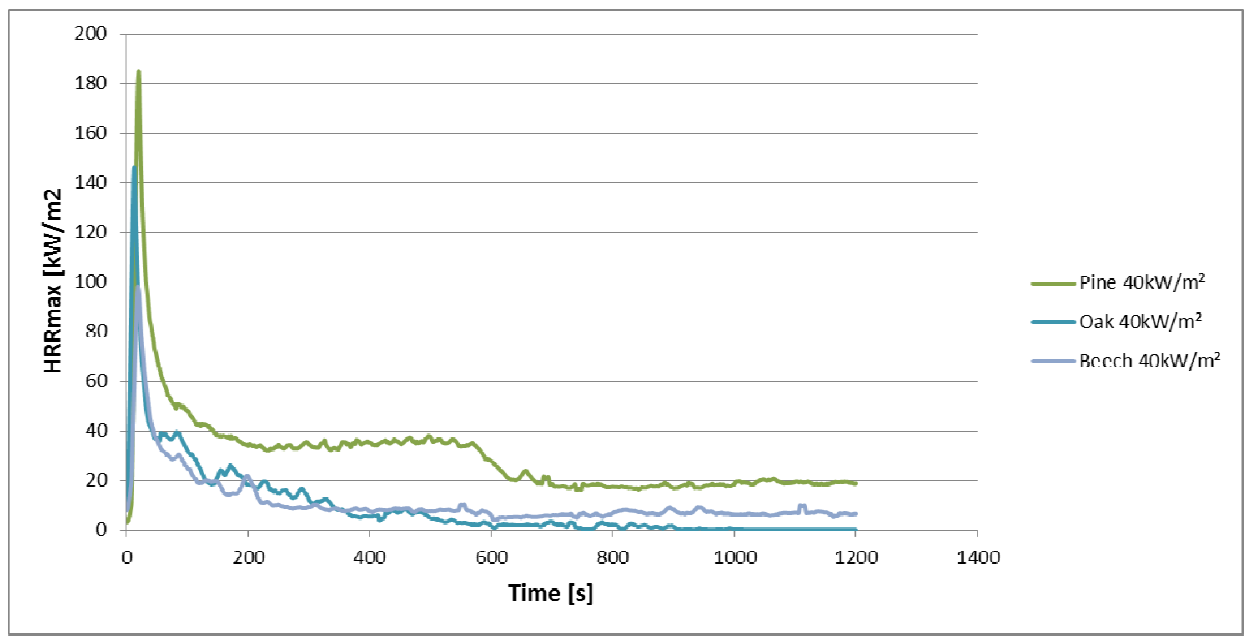

Fig. 2. Values of heat release rates of the tested materials at the lowest. heat exposures at which they were ignited in the time function of combustion of tested materials.

Figure 2 presents diagrams of the 3 tested litter types in which ignition took place at the same thermal flux density of $40 \mathrm{~kW} / \mathrm{m}^{2}$. Clearly seen were higher HRR values for pine litter, which reaches $H_{R R}$ max over $180 \mathrm{~kW} / \mathrm{m}^{2}$, then the HRR values rapidly decreased after a time of $200 \mathrm{~s}$ to a value lower than $40 \mathrm{~kW} / \mathrm{m}^{2}$. Until the end of the testing, the values of HRR were maintained at a similar level. Evidently the lowest values of $H_{R R}$ maxwere recorded for beech litter. In this case, the $H_{R R}$ max amounted to almost $100 \mathrm{~kW} / \mathrm{m}^{2}$, then the value of HRR would rapidly fall until a time of $200 \mathrm{~s}$ below $20 \mathrm{~kW} / \mathrm{m}^{2}$ and was maintained at a similar level, until the end of testing. For oak the $H_{R} R_{\max }$ value was higher than for beech litter by over $40 \mathrm{~kW} / \mathrm{m}^{2}$ and then kept falling in a similar way; and in the final round they achieve the lowest values.

An analysis (Table 1) of the value of maximum heat release rate intensity $\left(\mathrm{HRR}_{\max }\right)$ indicates that the highest value was obtained for spruce litter - over $200 \mathrm{~kW} / \mathrm{m}^{2}$. In the conducted tests the decidedly highest $H_{R R} R_{\max }$ values were recorded for coniferous trees, and the lowest $\mathrm{HRR}_{\max }$ value was achieved at $185 \mathrm{~kW} / \mathrm{m}^{2}$ for pine at an exposure equal to 40 $\mathrm{kW} / \mathrm{m}^{2}$. This shows that this type of biological material comprises diverse components, 
which serves as fuel during the combustion reaction during material combustion. The highest $\mathrm{HRR}_{\max }$ value for deciduous trees was obtained for oak litter at $40 \mathrm{~kW} / \mathrm{m}^{2}$ which approaches $79 \%$ of the lowest value of $H_{R R} \max$ of pine litter. The lowest result was achieved for beech litter $-98 \mathrm{~kW} / \mathrm{m}^{2}$. As compared to the highest result recorded for spruce litter, this approaches $41 \%$. The high $H_{R R} R_{\max }$ values for spruce may point to the composition of the litter, the major part of which was made up of minorconifer needles.

An analysis of the average heat release rate $H_{R R}$ av shows that the highest values were achieved in the testing of spruce litter $-50 \mathrm{~kW} / \mathrm{m}^{2}$. This tested litter is the only one to exceed the value of $150 \mathrm{~kW} / \mathrm{m}^{2}$ and is clearly the highest as compared to the remaining study materials, in which the value of $100 \mathrm{~kW} / \mathrm{m}^{2}$ had not been achieved. Furthermore, very similar results were obtained for pine and oak litter at a heat density stream amounting to $40 \mathrm{~kW} / \mathrm{m}^{2}$. The lowest $\mathrm{HRR}_{\mathrm{av}}$ values were achieved by two of the oak litter and one of the beech.

Given the ignition time of the tested material (Table1) it may be assumed that the parameters do not differ from the others. The ignition of oak litter took place quickly, and slightly later the spruce ignited - after $2 \mathrm{~s}$. The difference between extreme times amounted to $10 \mathrm{~s}$. Very similar parameters were recorded for two samples of pine, oak and beech at $40 \mathrm{~kW} / \mathrm{m}^{2}$. A considerable difference may be observed in values until time to ignition for oak, as at an intensified thermal flux density by $5 \mathrm{~kW} / \mathrm{m}^{2}$ ignition was achieved $6 \mathrm{~s}$ later. This proves that the greater the stream falling on the sample, the quicker that ignition takes place.

An analysis of the value of the total released heat (THR) pointed to a division of the tested materials into two groups. In the first group the highest values were achieved for coniferous litter of spruce and pine at a heat exposure of over $35 \mathrm{MJ} / \mathrm{m}^{2}$. In this comparison the highest value was achieved by spruce $46 \mathrm{MJ} / \mathrm{m}^{2}$. In the second group of samples consisting of oak and beech, the value of $14 \mathrm{MJ} / \mathrm{m}^{2}$ was not exceeded, which approaches $39 \%$ of the lowest value of the group of litters of coniferous trees. Between the highest and the lowest value the recorded difference was $36 \mathrm{MJ} / \mathrm{m}^{2}$ which approaches $26 \%$ of the value recorded for spruce. A study of the tested pine and oak litter found that with the intensifying density of thermal impact, the released heat tends to become reduced. As regards deciduous tree stands, the released heat is three-fold lower. This results from the properties and chemical ingredients of particular types of trees. At thermal exposition equalling $40 \mathrm{~kW} / \mathrm{m}^{2}$, the greatest amount of heat in test conditions was released by the pine litter by ca. $75 \%$ as compared to the litter of oak and beech with the same exposure.

An analysis of sample mass decreases expressed as percentages as compared to the initial mass has shown that all the values were quite similar. With the exception of oak, at a thermal exposureof radiation density equalling $40 \mathrm{~kW} / \mathrm{m}^{2}$ the difference between pine and beech amounts to approximately $10 \%$. A significant mass reduction was achieved by the oak litter. This result is higher by ca. $20 \%$ than the average of the remaining samples. The remaining values remain within the range of $63-73 \%$. Of considerable importance is the density, as well as the type of needles and leaves contained in the given research material. Given the exposure of $40 \mathrm{~kW} / \mathrm{m}^{2}$ the pine and oak litter was found to have one of the largest percentages of sample mass reduction.

A review of the smoke generation parameters of the litter allowed the presumption that the greatest speed of smoke emission (SPR) $-0.1351 \mathrm{~m}^{2} / \mathrm{s}$ was found for the pine litter - 40 $\mathrm{kW} / \mathrm{m}^{2}$. On the other hand, the lowest rate of smoke emission $-0.0271 \mathrm{~m}^{2} / \mathrm{s}$ was recorded for oak litter sample at $40 \mathrm{~kW} / \mathrm{m}^{2}$. As regards pine, at $40 \mathrm{~kW} / \mathrm{m}^{2}$ and $35 \mathrm{~kW} / \mathrm{m}^{2}$ a higher value of smoke emission was recorded at a higher thermal flux density.A different result was observed for oak litter- $40 \mathrm{~kW} / \mathrm{m}^{2}$ and $35 \mathrm{~kW} / \mathrm{m}^{2}$. The rate of smoke emission at an exposure of $40 \mathrm{~kW} / \mathrm{m}^{2}$ was higher by ca. $30 \%$ as compared to the oak emission rate by oak 
and beech litter. The lowest smoke emission rate of $0.0754 \mathrm{~m}^{2} / \mathrm{s}$ was recorded for a sample of oak litter.

A review of theemission values of carbon oxide indicated that higher $\mathrm{CO}$ emissions took place in litter obtained from deciduous tree stands. As regards litter of coniferous trees, their values are similar. The highest value recorded for beech was $1,295 \mathrm{~kg} / \mathrm{kg}$, the lowest one for spruce and pine. The higher the thermal flux density, the lower the emission of CO.

\section{Conclusions}

The following conclusions may be drawn from the conducted tests and based on the obtained results. The highest values of $\mathrm{HRR}_{\max }$ were achieved during testing of a sample of spruce litter at a thermal exposure amounting to $50 \mathrm{~kW} / \mathrm{m}^{2}$. This means, as compared to the remaining tested litter, that this particular litter releases more heat in the given time unit and has a clear effect on the rate and magnitude of fire spread in a forest, and in an indirect way on the ignition of subsequent litter in the adjacent forest zones. The litter of deciduous undergrowth requires a lower (by $5 \mathrm{~kW} / \mathrm{m}^{2}$ ) external heat flux indispensable for ignition. This is transposed on a greater likelihood of the occurrence of a fire in the event of a state of low humidity. Yet, as compared to litter of the coniferous tree stand they release less heat by $50 \%$.

The highest value of the $H_{R R}$ maxparameter was recorded in the phase of sample combustion, immediately after ignition. The greatest likelihood of fire spreading onto adjacent areas occurs in this phase. If there is no sample ignition, theHRR values for all the tested litters were similar (close to $15 \%$ ); nevertheless, the flameless ignition of litter in different heat and flow conditions than those used in the experimental studies may also pose a strong hazard with respect to fires, but they are characterised by the different dynamics of heat release and the rate of fire spreading for the adjacent habitats. Taking the $\mathrm{HRR}_{\mathrm{av}}$ values into consideration, it may be observed that at a similar thermal exposure (35 $\mathrm{kW} / \mathrm{m}^{2}-40 \mathrm{~kW} / \mathrm{m}^{2}$ ) the pine litter achieves the highest value by ca. $30 \%$ as compared to the $H_{R R}$ value for oak and beech. It may be assumed that the impact of the composition of a sample of pine resin contained in needles has an evident impact on the heat release rate. Taking into account only the heat exposure of $40 \mathrm{~kW} / \mathrm{m}^{2}$ of the average value, the heat release rate is presented by the below relation:

$\mathrm{HRR}_{\mathrm{av}}$ pine litter $>\mathrm{HRR}_{\mathrm{av}} \mathrm{Oak}$ litter $>\mathrm{HRR}_{\mathrm{av}}$ beech litter.

Taking into consideration the flammability of litter at $40 \mathrm{~kW} / \mathrm{m}^{2}$ the quickest ignition takes place for oak litter during a time of $2 \mathrm{~s}$. The above mentioned results were confirmed by results obtained during the reduction of a sample mass. Assuming the exposure of 40 $\mathrm{kW} / \mathrm{m}^{2}$, pine and oak litter achieves one of the highest values of mass loss reduction expressed as a percentage. The ignition time of the sample depended on the valueof the thermal flux density affecting the study material- the higher the HRR value, the shorter the time until ignition. An analysis of parameters related to the emission of fire gases, such as carbon oxide in the event of samples characterised by ignition, indicated a higher amount of $\mathrm{CO}$ in deciduous tree-stand litter as compared to litter of coniferous trees by ca. $20 \%$.

On the basis of the conducted research the following final conclusions may be formulated:

- The highest fire hazard is caused by the litter of coniferous trees owing to the greater heat they release during combustion, which leads to a fire spreading.

- The maximum rate of heat release was achieved by spruce litter at $240 \mathrm{~kW} / \mathrm{m}^{2}$, but at a thermal exposure equalling to $50 \mathrm{~kW} / \mathrm{m}^{2}$.

- For an oak sample at anexposure equalling $40 \mathrm{~kW} / \mathrm{m}^{2} \mathrm{t}$, he highest mass loss was recorded at a level of $91 \%$ (different from the remaining ones $20 \%$ ). 
- Litters that do not ignite released the highest amount of smoke, primarily as regards pine and oak.

- With the growth of the thermal flux density the average carbon oxide emission decreases.

- The biggest rate of mass decrease was recorded for pine litter at an exposure of the thermal flux density $30 \mathrm{~kW} / \mathrm{m}^{2}$ amounting to $4.74 \mathrm{~g} / \mathrm{s}$. This value was on average by 9.9 fold higher than the value of the remaining tested samples.

- At similar thermal exposure $\left(35 \mathrm{~kW} / \mathrm{m}^{2}-40 \mathrm{~kW} / \mathrm{m}^{2}\right)$ of values of the $H_{R R}$ avparameter the pine litter was found to have the highest value, higher by ca. $30 \%$ as compared to the $\mathrm{HRR}_{\mathrm{av}}$ value for oak and beech. The impact exerted by the composition of a litter sample obtained from pine needles containing resin has an evident influence on the heat release rate.

- The rate of smoke emission at the exposure of $40 \mathrm{~kW} / \mathrm{m}^{2}$ was higher by ca. $30 \%$ as compared to the rate of smoke emission by the litter of oak and beech. The smallest smoke emission rate of $0.0754 \mathrm{~m}^{2} / \mathrm{s}$ was recorded for a sample of oak litter.

\section{References}

1. M. Calviño-Cancela, P. Lorenzob, L. Gonzálezc, For. Ecol.Manag., 409, 826, (2018)

2. J. Zarzycki, Bezp. poż. las. (Warszawa, 2016)

3. A. Łukaszek, M. Półka, M. Bednarek, Annals WULS - SGGW, 75, 54,(2011)

4. A. Łukaszek, M. Półka, M. Konecki, Annals WULS - SGGW, 75, 59, (2011)

5. V. Babrauskas, Devel. of the Cone Calor. - A Bench-Scale Heat Release Rate Appar. Based on Oxy. Consum., (NIST, 1982)

6. M. Swan, H. Sitters, J. Cawson, T. Du, Y. Wibisono, A. YorkFor. Ecol.Manag., 415416, 85(2018)

7. A. Ganteaume, J. Marielle, L. Corinne, C. Thomas, B. Laurent, For. Ecol. Manag., 261, 2223, (2011)

8. ISO 5660: Reaction-to-fire tests - Heat release, smoke production and mass loss rate" 